\title{
Diabetic retinopathy and visual impairment in disaster prone coastal population of Bangladesh
}

\author{
M. Abu Sayeed ${ }^{1}$, AH Syedur Rahman ${ }^{2}$, Md. Hazrat $\mathrm{Ali}^{2}$, \\ Mir Masudur Rhaman ${ }^{1}$, J Ashraful Haq ${ }^{1}$ and Akhter Banu ${ }^{3}$ \\ ${ }^{1}$ Department of Community Medicine, Ibrahim Medical College (IMC), Dhaka; ${ }^{2}$ Department of \\ Ophthalmology, Bangladesh Institute of Research and Rehabilitation in Diabetes and Endocrine \\ Metabolic Disorders (BIRDEM); ${ }^{3}$ Institute of Nutrition and Food Science (INFS), University of Dhaka
}

\begin{abstract}
Background and objective - Disaster prone coastal population has least accessibility to health care and very little is known about the prevalence of diabetes, diabetic retinopathy (DR) and visual impairment. This study addressed the prevalence of visual impairment and DR and risk factors related to DR among population residing in disaster prone areas of Bangladesh.

Methods: Thirty-two coastal communities in six coastal districts were purposively selected. All coastal people of age 18 years or more were considered eligible. Investigations included clinical history, anthropometry (height, weight, waist- and hip-girth), blood pressure and fasting blood glucose (FBG). The participants with hyperglycemia (FBG $\geq 5.6 \mathrm{mmol} / \mathrm{l}$ ) were undertaken for eye examination. Visual acuity was measured bilaterally using the Snellen chart. An Early treatment diabetic retinopathy study (ETDRS) cut out chart with E Optotypes was used.

Results: A total of 7567 participants volunteered and 1540 had hyperglycemia (FBG $\geq 5.6 \mathrm{mmol} / \mathrm{l})$. Of the hyperglycemic participants, $1214(91.7 \%)$ participated for complete eye examination. Visual impairment of any type was found in $14.1 \%$, any type cataract in $27.8 \%$ and any type DR in $18 \%$. The participants of advancing age of higher social class and higher central obesity had excess risk for developing DR. The participants with known family history of diabetes also had greater risk. Compared with the group having FBG 5.6 - 6.9mmol/1 those having FBG $>6.9 \mathrm{mmol} / 1$ had significant risk for DR (OR 3.11, 95\% CI 2.04 - 4.76).

Conclusion: The study concludes that visual impairment and cataract of any type is almost comparable with other coastal populations. The coastal people had higher prevalence of DR compared to rural population from other areas of Bangladesh and it was also higher than global estimate. The persons with higher age from higher social class with higher central obesity had excess risk for DR. The risk of DR increased with increasing hyperglycemia. Further study may be undertaken to confirm these findings.
\end{abstract}

IMC J Med Sci 2016; 10(1): 10-17

\section{Introduction}

Of the alarming trend of non-communicable diseases (NCD), type 2 diabetes mellitus (T2DM) is common throughout the world and more alarming in the south-east Asian region [1]. A global estimate of diabetes in the year 2000 was 171 million. This figure is likely to be more than double (366 million) by 2030; and most significant

Address for Correspondence:

Prof. M. Abu Sayeed, Department of Community Medicine, Ibrahim Medical College, 122 Kazi Nazrul Islam Avenue, Shahbag, Dhaka-1000.email: sayeed@imc.ac.bd 
increase will occur in the developing countries [1]. T2DM affects elderly people in the developed countries, whereas, in the developing and least developing countries, younger people are more affected [2]. We have the same experience in Bangladesh [3]. Additionally, the prevalence of micro-vascular complications is common in these populations [4-6]. Of the micro-vascular sequels, diabetic retinopathy (DR) was found to be the most disabling complications as it results into loss of vision. A community based study in Sri Lanka reported that more than one-fourth $(27.4 \%)$ of the diabetic patients had DR [7]. This report indicates that the most diabetic people are prone to develop DR and eventually blindness. For Bangladesh, several population based studies reported the increasing trend of T2DM [8-10]; but there was no community based study on DR. This study addressed the prevalence and risk of DR at the community level in a disaster prone coastal population of Bangladesh.

\section{Material and methods}

The study protocol was approved by the Ethical Review Committee of the Diabetic Association of Bangladesh (BADAS).

Study area and population. A disaster prone population of coastal area was purposively selected. A total of 32 geographical sites [18 secondary schools, 5 primary schools, 5 Madrasahs (religious schools) including 4 Union Councils] were selected purposively in six coastal districts of Barisal, Borguna, Vola, Pirojpur, Potuakhali and Jhalokathi. The study areas were reported elsewhere [11] and is shown in Fig 1 and 2. The investigations at community level started on $17^{\text {th }}$ September 2013 and ended on $12^{\text {th }}$ May 2014. At the start, we made contact with the teachers and the students of the selected institutions. We discussed the proposed study with them informing the objectives and the investigation procedure in detail. All parents, guardians, neighbors and relatives of the students and teachers were invited to participate. All villagers of age 18 years or more were considered eligible. The students and teachers volunteered to inform the villagers about the study. Additionally, volunteers prepared the list of the interested participants. Informed consent was taken from each participant and was advised to attend the investigation site in the next morning with an overnight fast the algorithm of the study is shown in Fig 3.

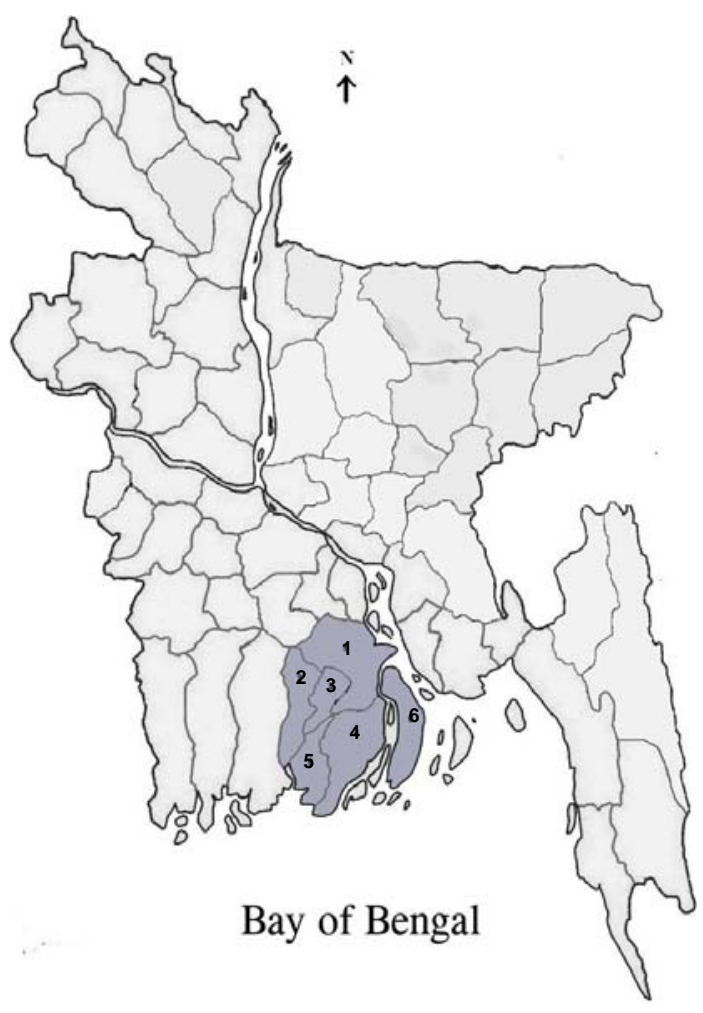

Fig.1: Map of Bangladesh showing the location of six coastal districts included in the study [11]

Note: 1-Barisal, 2-Pirojpur, 3-Jhalokhati, 4-Patuakhali, 5-Barguna, 6-Bhola

Interviewing, measurement of anthropometry and blood pressure: In the morning, the participant was interviewed about occupation, education, income, illness (present or past) and medication. Interview on family-history included diabetes, hypertension (HTN), stroke, coronary heart diseases (CHD), peripheral vascular disease (PVD), foot-ulcer and leg amputation. The anthropometric measurements were height, weight, waist- and hip-girth. Body mass index (BMI = weight in $\mathrm{kg} /$ height in met sq.) and waist-to-hip ratio (WHR $=$ waist $/$ hip) were calculated. Blood pressure was measured after 10 min rest with standard cuff, fitted with mercury sphygmomanometer. A mean of the two measures was accepted. 


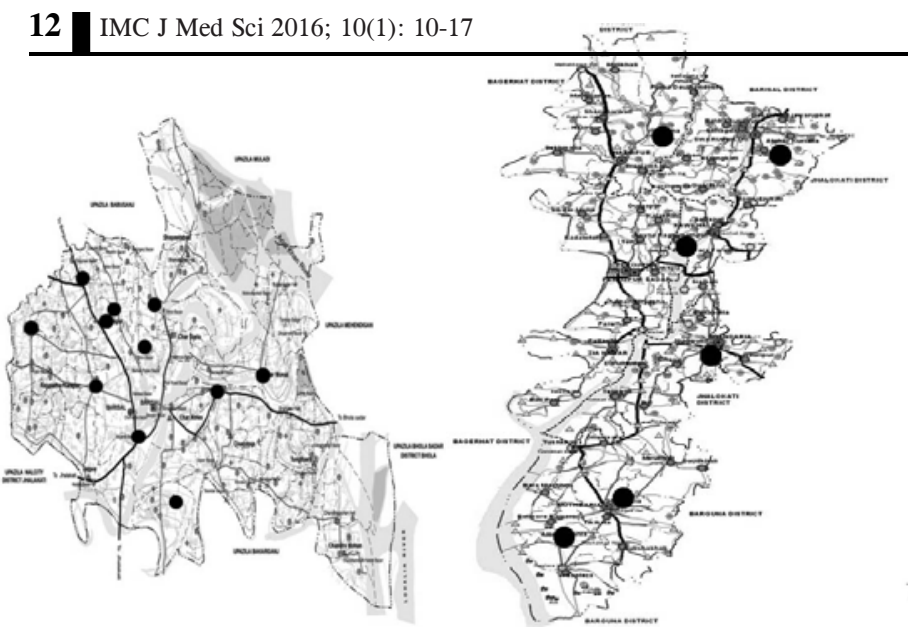

Barisal

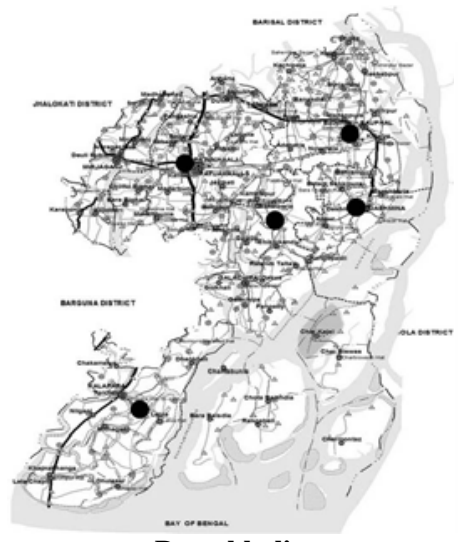

Patuakhali
Pirojpur

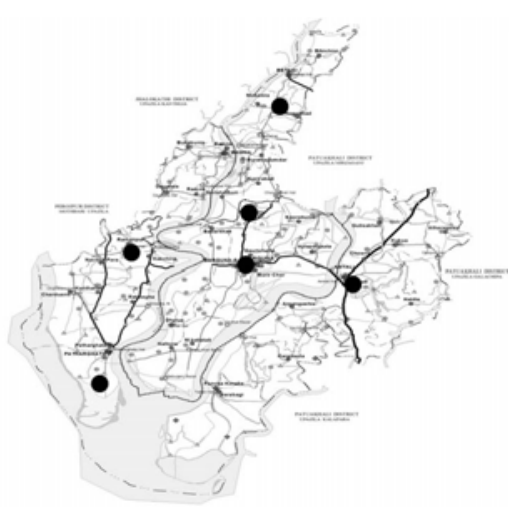

Barguna

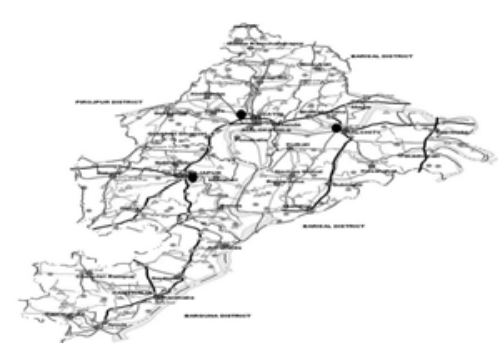

Jhalokhati

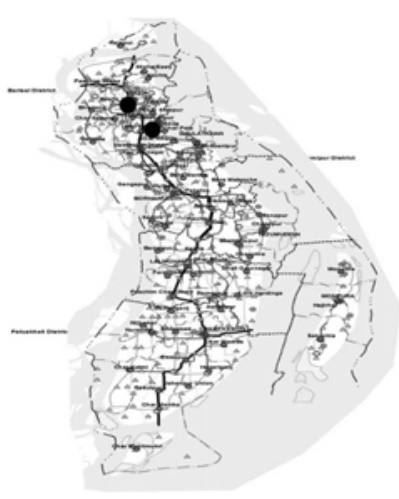

Bhola

Fig.2: Map showing the study sites in each coastal district. Each Dot (๑) indicates location of study site [11]

Collection of blood sample: Taking an aseptic measure five $\mathrm{ml}$ of fasting blood sample was collected for estimation of fasting blood glucose (FBG $\mathrm{mmol} / \mathrm{l}$ ) and lipids (total cholesterol [Tchol], triglycerides [TG], low-density lipoprotein [LDL] and high-density lipoproteins [HDL]). Finally, biochemical tests were carried out in BIRDEM laboratory. Plasma glucose was measured by glucose oxidase-peroxidase method using Technicon M-II auto-analyzer. To reduce the cost, a randomized sample was drawn $(n=225)$ for the estimation of T-chol, TG and HDL by autoanalyzer (Hitachi-704) using enzymatic method. The coefficient of variation (CV) was allowed $\leq 5 \%$. While collecting blood sample a drop of blood was taken on a hemo-glucotest strip (One Touch select sample, Lifescan) for rapid assessment of FBG [12]. We used ADA and WHO diagnostic criteria for hyperglycemia and predicting diabetes $[13,14]$. The participants, who showed FBG $\geq 5.6 \mathrm{mmol} / \mathrm{l}$, were referred to ophthalmologist for eye examination (Fig 3). The participants presented with eye complaints, irrespective of glycemic status, were also referred.

Eye examinations: This included visual acuity test and fundoscopy by a two-member team of the ophthalmologists. Both ophthalmologists had the experience of eye examination in the department of ophthalmology at BIRDEM hospital. It may be noted that BIRDEM, a national referral center for endocrine disorders, where these ophthalmologists examine about 100 diabetic patients daily for the diagnosis of DR. 


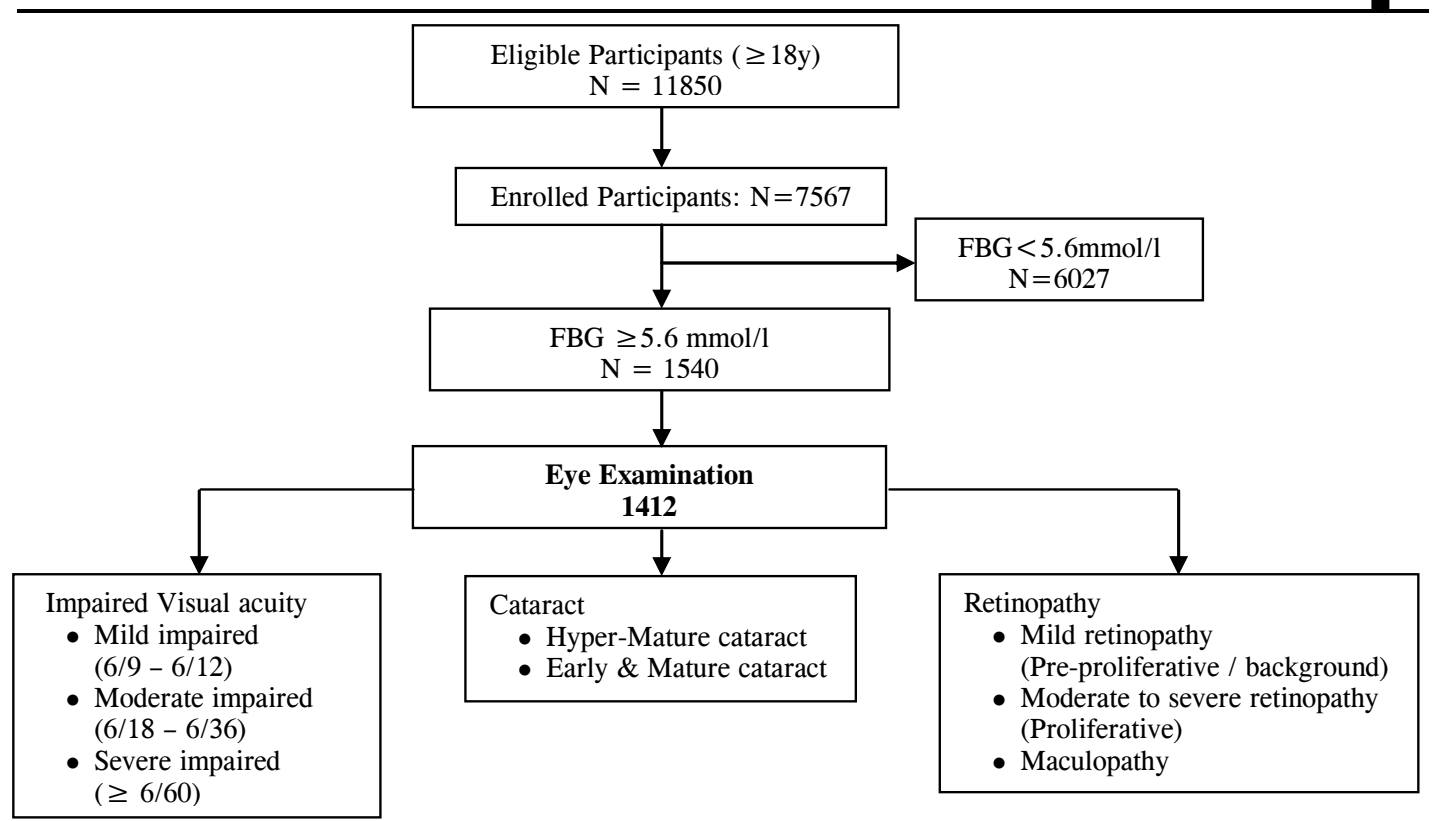

Fig-3: Algorithm of the study

Visual acuity was measured bilaterally using the Snellen chart. An early treatment diabetic retinopathy study (ETDRS) cut out chart with E Optotypes was used [15]. Torch light and pinhole were also used [16]. The cause of visual impairment (cataract, refractive error and retinopathy) was identified $[16,17]$. Then the pupil was dilated by using $1 \%$ Tropicamide and the fundus was examined with direct ophthalmoscope [18]. Diabetic retinopathy (DR) was diagnosed and classified according to classification of DR and diabetic macular edema [19]. The study findings on DR have been modified for easy presentation: (a) Pre-proliferative - microaneurysms with or without intraretinal hemorrhages; (b) proliferative neovascularization with or without Vitreous/preretinal hemorrhage; (c) Diabetic macular edema (maculopathy) - any thickening or lipid exudates in the macula [20].

\section{Statistical analyses}

The prevalence rates of cataract, impaired visual acuity and diabetic retinopathy according to sex, family history and social class were given in percentages with $95 \%$ confidence interval (CI). The biophysical characteristics were shown in mean with standard deviation. We used unpaired $t-$ test for comparison of characteristics between participants with and without retinopathy. For assessment of risk odds ratio (OR) with $95 \%$ CI were used. SPSS version 20 was used for all analyzing qualitative and quantitative data. Less than 0.05 was considered significant.

\section{Results}

According to eligibility criteria (age $\geq 18 y$ ), as mentioned above, a total of 11,850 were found eligible (Fig 3). Of them, 7567 (63.85\%) took part in the investigation. The prevalence of hyperglycemia (FBG $\geq 5.6 \mathrm{mmol} / \mathrm{l}$ ) was found in $1540(20.4 \%)$. Of them, 1412 (91.7\%) volunteered eye examination. The prevalence (with $\mathrm{CI}$ ) of cataract, impaired visual acuity and diabetic retinopathy was $27.8(25.57-30.23), 14.1$ (12.28 - 15.92) and 17.9 (15.90 - 19.90), respectively (Table 1).

The prevalence of DR according to sex, social class and family history were shown in table 2 . The prevalence of DR was significantly higher among those who had known diabetic member in their first degree relatives than those who had no known diabetic member in their families. Regarding social class, the affluent participants had 
significantly higher DR than their non-affluent counterparts. Compared with the women the men had higher frequency though not significant.

Table-1: Prevalence [\% (95\% CI*)] of cataract, impaired visual acuity and retinopathy $(n=1412)$

\begin{tabular}{ccc}
\hline Cataract & $\mathrm{n}$ & $\%(95 \% \mathrm{CI})$ \\
\hline a. No Cataract & 1018 & $72.1(69.77-74.43)$ \\
b. Cataract & & \\
Early + Mature & 256 & $18.1(16.1-20.1)$ \\
Hyper-mature & 138 & $9.8(8.25-11.25)$ \\
Total cataract & 394 & $27.9(25.57-30.23)$
\end{tabular}

\begin{tabular}{|c|c|c|}
\hline Visual acuity & & \\
\hline a. Normal (6/6) & 1213 & $85.9(84.08-87.32)$ \\
\hline b. Impaired & & \\
\hline Mild (6/9-6/12) & 103 & $7.3(5.95-8.65)$ \\
\hline Moderate (6/18-6/36) & 53 & $3.8(2.8-4.8)$ \\
\hline Severe $(=>6 / 60)$ & 43 & $3.0(2.1-3.9)$ \\
\hline Total impaired & 199 & $14.1(12.28-15.92)$ \\
\hline Diabetic Retinopathy & & \\
\hline a. Absent & 1158 & $82.0(84.0-82.0)$ \\
\hline b. Present & & \\
\hline $\begin{array}{l}\text { Mild (pre-proliferative } \\
\text { / background) }\end{array}$ & 170 & $12(10.31-13.69)$ \\
\hline $\begin{array}{l}\text { Moderate to severe } \\
\text { (proliferative) }\end{array}$ & 44 & $3.1(2.20-4.00)$ \\
\hline $\begin{array}{l}\text { Maculopathy } \\
\text { (macular edema) }\end{array}$ & 40 & $2.8(1.94-3.66)$ \\
\hline $\begin{array}{l}\text { Total diabetic } \\
\text { retinopathy }\end{array}$ & 254 & 17.9 (15.90-19.90) \\
\hline
\end{tabular}

$C I^{*}$ - confidence interval

Table-2: Prevalence [\% (95\% CI*)] of retinopathy according to sex, family history $(n=1412)$ and social class $(n=1377)$

\begin{tabular}{lcc}
\hline Variables & $\mathrm{n}$ & $\%\left(95 \% \mathrm{CI}^{*}\right)$ \\
\hline $\begin{array}{l}\text { Sex } \\
\text { (n: men/women= 585/827) }\end{array}$ & & \\
$\quad \begin{array}{l}\text { Men } \\
\quad \text { Women }\end{array}$ & 126 & $21.5(17.67-24.83)$ \\
Family history of diabetes & & $15.5(13.03-17.97)$ \\
\hline (n: Absent/Present= 833/579) & & \\
$\quad \begin{array}{l}\text { Absent (or not known) } \\
\text { Present }\end{array}$ & 113 & $13.6(11.29-15.91)$ \\
$\begin{array}{l}\text { Social class } \\
\text { (n: Non affluent/affluent= }\end{array}$ & 141 & $24.4(20.91-27.89)$ \\
480/897) & & \\
$\quad$ Non affluent (poor) & 63 & $13.1(10.08-16.12)$ \\
Affluent (middle and rich) & 184 & $20.5(17.85-23.15)$ \\
\hline CI* - confidence interval & &
\end{tabular}

Table-3: Comparison of characteristics between participants with and without retinopathy

\begin{tabular}{lccccc}
\hline & \multicolumn{2}{c}{$\begin{array}{c}\text { No retinopathy } \\
\text { n=617 }\end{array}$} & \multicolumn{2}{c}{$\begin{array}{c}\text { Retinopathy } \\
\text { n=145 }\end{array}$} & \\
\cline { 2 - 5 } Characteristics & Mean & SD† & Mean & SD & p $\neq$ \\
\hline Age $(\mathrm{y})$ & 47.7 & 13.4 & 52.4 & 12.8 & 0.001 \\
BMI & 23.6 & 3.9 & 23.6 & 3.5 & .917 \\
WHR & 0.896 & 0.081 & 0.925 & 0.072 & 0.001 \\
WHTR & 0.507 & 0.072 & 0.523 & 0.061 & .010 \\
SBP $(\mathrm{mmHg})$ & 127.4 & 21.9 & 129.8 & 24.2 & .238 \\
DBP $(\mathrm{mmHg})$ & 81.8 & 12.6 & 81.9 & 11.1 & .921 \\
FBG $(\mathrm{mmol} / \mathrm{l})$ & 6.8 & 3.1 & 8.9 & 4.5 & 0.001 \\
Chol $(\mathrm{mg} / \mathrm{dl}) *$ & 221 & 69 & 189 & 48 & .030 \\
TG $(\mathrm{mg} / \mathrm{dl})^{*}$ & 176 & 122 & 150 & 82 & .323 \\
HDL $(\mathrm{mg} / \mathrm{dl}) *$ & 46.2 & 10.4 & 44.5 & 11.4 & .468 \\
LDL $(\mathrm{mg} / \mathrm{dl}) *$ & 139.9 & 59.6 & 114.6 & 41.5 & .047 \\
\hline
\end{tabular}

$\dagger$ SD - standard deviation; $¥ \mathrm{p}$ after unpaired t-test; * - a randomized sample size $(n=225)$

Table-4: Prevalence (\%) and Risk factors estimated for retinopathy

\begin{tabular}{|c|c|c|c|c|}
\hline Risk variables & $\%$ & OR† & $\begin{array}{c}95 \% \\
\left.\mathrm{C}^{*}\right)\end{array}$ & $p$ \\
\hline \multicolumn{5}{|l|}{ Sex } \\
\hline Women & 18.5 & 1 & - & \\
\hline Men & 19.8 & 1.09 & $0.75-1.57$ & 0.66 \\
\hline \multicolumn{5}{|l|}{ Social class } \\
\hline Poor & 14.0 & 1 & - & \\
\hline Middle + Rich & 21.1 & 1.54 & $1.01-2.35$ & .047 \\
\hline \multicolumn{5}{|l|}{ Family history of diabetes } \\
\hline Absent or not known & 15.5 & 1 & - & \\
\hline Present & 23.1 & 1.52 & $1.05-2.20$ & .028 \\
\hline \multicolumn{5}{|l|}{ Glycemic status(FBG, mmol/l) } \\
\hline NFG $(<5.6)$ & 12.7 & 1 & - & \\
\hline IFG $(5.6-6.9)$ & 13.3 & 1.05 & $0.61-1.81$ & .850 \\
\hline $\mathrm{DM}(>6.9)$ & 31.3 & 3.11 & $2.04-4.76$ & .000 \\
\hline \multicolumn{5}{|l|}{ Age quartile $(y)$} \\
\hline Quartile $1(<30)$ & 9.9 & 1 & - & \\
\hline Quartile $2(<31-40)$ & 12.9 & 1.35 & $0.58-3.17$ & .485 \\
\hline Quartile $3(<41$ - 55) & 19.8 & 2.25 & $1.03-4.94$ & .043 \\
\hline Quartile 4 (>55) & 26.4 & 3.27 & $1.48-7.19$ & .003 \\
\hline \multicolumn{5}{|l|}{ BMI quartile } \\
\hline Quartile $1(<19.5)$ & 15.6 & 1 & - & \\
\hline Quartile $2(<19.6-21.9)$ & 18.0 & 1.19 & $0.61-2.33$ & .618 \\
\hline Quartile $3(<22.0-24.8)$ & 22.3 & 1.55 & $0.82-2.92$ & .178 \\
\hline Quartile 4 (>24.8) & 18.6 & 1.23 & $0.66-2.32$ & .515 \\
\hline \multicolumn{5}{|l|}{ WHR quartile } \\
\hline Quartile $1(<0.81)$ & 12.1 & 1 & - & \\
\hline Quartile $2(<0.82-0.87)$ & 12.2 & 1.01 & $0.48-2.13$ & .982 \\
\hline Quartile $3(<0.88-0.93)$ & 21.4 & 1.98 & $1.03-3.79$ & .040 \\
\hline Quartile $4(>0.93)$ & 23.8 & 2.28 & $1.22-4.23$ & .009 \\
\hline
\end{tabular}


Table 3 showed the comparisons of biophysical characteristics between participants with and without DR. The participants with DR had significantly higher age $(\mathrm{p}<0.001)$, higher central obesity (WHR $\mathrm{p}<0.001$; and WHtR $\mathrm{p}=0.01$ ), higher fasting FBG $(p<0.001)$. Interestingly, there was no significant difference in general obesity (BMI $\mathrm{p}=0.917$ ). Even more interesting is that the participants with DR had significantly lower total cholesterol $(p=0.03)$ and lower low-density lipoprotein (LDL $\mathrm{p}=0.047)$.

The risk factors related to DR was shown in Table 4. Compared with the non-affluent, the affluent participants had higher risk (OR 1.54, 95\% CI, 1.01 - 2.35). Likewise, the participants from known diabetic family had greater risk (OR 1.52, CI, 1.05 - 2.20) than their counterparts having no known diabetes in their families. The participants with diabetes had excess risk (OR 3.11, CI, 2.04 4.76) than those with normal (NFG) or impaired fasting glucose (IFG). For an increasing age, higher the quartiles greater is the risk. Similarly, higher is the central obesity (WHR) more is the risk (Table 4); whereas, general obesity (BMI) was found to have no effect on DR.

\section{Discussion}

This is the first study, which addressed the prevalence of DR and visual impairment in a coastal population. Some socio-demographic and biophysical risk factors were also assessed. Two important aspects of the study are worth mentioning. Firstly, the study population has least access to health care services and diagnostic facilities. Secondly, the study areas are mostly inaccessible due to inconvenient communication and precarious weather condition. We had some advantages. We could refer the persons with cataract to nearby centers for surgery organized and maintained by Fred Hollow Foundation. The local people especially teachers and students were very much cordial. They actively and sincerely volunteered the study in every step (carrying message to the villagers from house to house and making list of the participants and taking them to the investigation site.

There are few published studies on the prevalence of visual impairment and cataract among coastal population for comparisons. Patil $\mathrm{S}$ et al reported very high prevalence of impaired visual acuity $(33.0 \%)$ and cataract $(82.4 \%)$ in Sindhudurg district on the western coastal strip of India [21]. They reported high prevalence among coastal population may be due to higher age group ( $>50 \mathrm{y}$ ) they studied.

So far available a population based study of Bangladesh showed that overall prevalence of DR was $5.4 \%$ among the rural people of age 30 years or older [22]. Our study demonstrated that compared with the rural people of other areas of Bangladesh, the coastal people had increased prevalence of DR. An estimated global prevalence of 'any DR' was found $6.96 \%$ (95CI, 6.87-7.04) [23]. Thus, the global estimate also indicates that the coastal people are more susceptible for developing DR. A 'Singapore Eye Study' among the migrant Indians (age $>40 y$ ) reported that the prevalence of DR was $10.5 \%$ (95\% CI, 9.3-11.8) [24]. This finding also showed that our study population bears greater risk for DR.

With regard to risk factors, we found persons with advancing age, higher class with family history of diabetes had excess risk for DR. These findings are consistent with other studies [20 - 23]. In contrast, the Singapore study [24] observed that lower income and living in smaller houses were associated with vision threatening DR.

An interesting finding was that the level of total cholesterol and LDL-cholesterol was found significantly lower in those who had no DR than those who had. The findings indicate that these lipid fractions appear to be protective against DR. The explanation is not known.

We had some limitations. The sampling technique was a purposive one. We could not include dietary habit (salt, fruits and vegetables), physical activities and housing status. We could not afford two important but relevant investigations like hemoglobin Aic and stereoscopic digital photography.

\section{Conclusion}

We conclude that the prevalence of visual impairment and cataract is comparable with other studies; whereas, the prevalence of DR among the 
coastal people was higher than that of the rural Bangladeshis and also higher than global estimates and Indian migrants. The persons with higher age from higher social class with higher central obesity had excess risk for both diabetes and DR. Further study may be undertaken to confirm the study findings and if found consistent then the coastal people need an urgent Eye Care facilities for the prevention of visual impairment and blindness.

Acknowledgements - We are grateful to Fred Hollow Foundation (FHF) for their financial support. We are indebted to Prof AH Syedur Rahman, Department of Ophthalmology, BIRDEM for his initiative to communicate to FHF. We deeply acknowledge him posthumously with all our deepest respect. We appreciate the cooperation extended by the Ibrahim Medical College and the Department of Ophthalmology, BSMMU, Dhaka. We are grateful and obliged to the teachers, students and all participants of coastal area for their cordial and pleasant hospitality.

\section{References}

1. Wild S, Roglic G, Green A, Sicree R, King $\mathrm{H}$ : Global Prevalence of Diabetes: Estimates for the year 2000 and projections for 2030. Diabetes Care 2004; 27: 1047-1053.

2. World Health Organization: Guidelines for the prevention, management and care of diabetes mellitus. EMRO Technical publications series 32, Geneva 2006.

3. Khanam PA, Mahtab H, Ahmed AU, Sayeed MA, Azad Khan AK. In Bangladesh diabetes starts earlier now than 10 years back: a BIRDEM study. Ibrahim Med Coll J 2008; 2(1): 1-3

4. Sayeed MA, Khanam PA, Choudhury RI, Mahtab H, Azad Khan AK. Retinopathy and nephropathy are the most prevalent complications among diabetic subjects in Bangladesh. Diabetologia 2005; 48(Suppl 1): Abs-944 (P: A343).

5. Khan S, Khanam P, Latif Z, Mahtab H, Azad Khan AK, Banu A, Sayeed MA. Nephropathy was the most frequent complication among people with diabetes after a 10 -year follow up (p243, Abs). Diabetes UK, Diabetic Medicine 2006; 23[suppl-4]: 95

6. Sayeed MA, Khanam PA, Mahtab H and Azad Khan AK. Microvascular complications among diabetic subjects predominate in the long-term follow up: 15-year retrospective study. Diab Res Clin Pract 2000; 50: S116.

7. Katulanda P, Priyanga Ranasinghe $P$ and Jayawardena R. Prevalence of retinopathy among adults with self-reported diabetes mellitus: the Sri Lanka diabetes and Cardiovascular Study. BMC Ophthalmol 2014; 14: 100. doi: $10.1186 / 1471-2415-14-100$

8. Sayeed MA, Mahtab H, Khanam PA, Latif ZA, Banu A and Azad Khan AK. Prevalence of diabetes and impaired fasting glucose in urban population of Bangladesh. Bangladesh Med Res Counc Bull 2007; 33(1): 1-12.

9. Sayeed MA, Rhaman MM, Fayezunnessa N, Khanam PA, Begum T, Mahtab $\mathrm{H}$ and Banu A. Childhood diabetes in a Bangladeshi population. Journal of Diabetes Mellitus 2013; 3(1): 33-37.

10. Rahim MA, Hussain A, Azad Khan AK, Sayeed MA, Keramat Ali SM, Vaaler S. Rising prevalence of type 2 diabetes in rural Bangladesh: a population based study. Diabetes Res Clin Pract 2007; 77(2): 300305.

11. Sayeed MA, Syedur Rahman AH, Hazrat Ali M, Subrina Afrin, Masudur Rhaman M, Mainul Hasan Chowdhury $\mathbf{M}$ and Banu A. Prevalence of hypertension in people living in coastal areas of Bangladesh. Ibrahim Med Coll J 2015; 9(1): 11-17.

12. Florkowski C, Budgen C, Kendall D, Lunt H and Moore MP. Comparison of blood glucose meters in a New Zealand diabetes centre. Ann Clin Biochem 2009; 46: 302-305.

13. Gabir MM, Hanson RL, Dabelea D, Imperatore G, Roumain J, Bennett PH and Knowler WC. The 1997 American Diabetes Association and 1999 World Health Organization criteria for hyperglycemia in the diagnosis and prediction of diabetes. Diabetes Care 2000; 23(8): 1108-1112. 
14. American Diabetes Association. Standards of Medical Care in Diabetes-2011. Diabetes Care 2011; 34(Suppl 1): S11-S61.

15. Focal photocoagulation treatment of diabetic macular edema. Relationship of treatment effect to fluorescein angiographic and other retinal characteristics at baseline: ETDRS report no. 19. Early Treatment Diabetic Retinopathy Study Research Group. Arch Ophthalmol 1995; 113: 1144-1155.

16. Neena J, Rachel J, Praveen V, Murthy GV. Rapid assessment of avoidable blindness in India. PLOS One 2008; 3: e2867.

17. Prajna NV, Venkataswamy G. Cataract blindness-The Indian Experience. Bull World Health Organ 2007; 79:259-60.

18. Klein R, Klein BEK, Moss SE, Davis MD, Demets DL. The Wisconsin epidemiologic study of diabetic retinopathy-X. Four year incidence and progression of diabetic retinopathy, when age at diagnosis is 30 years or more. Arch Ophthalmol 1989; 107: 244-49.

19. Wilkinson CP, Ferris FL, 3rd, Klein RE, et al. Proposed international clinical diabetic retinopathy and diabetic macular edema disease severity scales. Ophthalmology 2003; 110: $1677-82$.
20. Ciulla TA, Amador AG, Zinman B. Diabetic retinopathy and diabetic macular edema: pathophysiology, screening, and novel therapies. Diabetes Care 2003; 26(9): 2653-64.

21. Patil S, Gogate P, Vora S, Ainapure S, Hingane RN, Kulkarni AN, Shammanna BR. Prevalence, causes of blindness, visual impairment and cataract surgical services in Sindhudurg district on the western coastal strip of India. Indian J Ophthalmol 2014; 62(2): 240-45.

22. Akhter A, Fatema K, Ahmed SF, Afroz A, Ali L, Hussain A. Prevalence and associated risk indicators of retinopathy in a rural Bangladeshi population with and without diabetes. Ophthalmic Epidemiol 2013; 20(4): 220-7.

23. Yau JW, Rogers SL, Kawasaki R, Lamoureux EL, Kowalski JW, Bek T, et al, MetaAnalysis for Eye Disease (META-EYE) Study Group. Global prevalence and major risk factors of diabetic retinopathy. Diabetes Care 2012; 35(3): 556-64.

24. Zheng $\mathrm{Y}$, Lamoureux EL, Lavanya R, Wu $\mathrm{R}$, Ikram MK, Wang JJ, Mitchell $\mathrm{P}$ et al. Prevalence and risk factors of diabetic retinopathy in migrant Indians in an urbanized society in Asia: the Singapore Indian eye study. Ophthalmology 2012; 119(10): 2119-24. 